\title{
IMPLEMENTASI TEKNOLOGI VIRTUAL REALITY PADA MEDIA PEMBELAJARAN PERAKITAN KOMPUTER
}

\author{
Hari Antoni Musril ${ }^{1}$, JasmientiX ${ }^{2}$, Mifta Hurrahman $^{3}$ \\ ${ }^{1,2,3}$ Program Studi Pendidikan Teknik Informatika dan Komputer, FTIK, IAIN Bukittinggi \\ Bukittinggi, Indonesia
}

e-mail: hari.antonimusrril@iainbukittinggi.ac.id ${ }^{1}$, jasmienti@iainbukittinggi.ac.id², miftahurrahman95@gmail.com³

\begin{abstract}
Abstrak
Penelitian dilatar belakangi oleh masalah yang terjadi pada pembelajaran perakitan komputer. Pada saat pembelajaran dilakukan tidak didukung oleh jumlah komponen hardware komputer yang sesuai dengan jumlah siswa, sehingga siswa sulit untuk memahami dan mempraktekkan materi pelajaran. Terbatasnya jumlah komponen peraga disebabkan karena keterbatasan anggaran untuk pengadaan. Komponen peraga yang ada di Sekolah banyak yang rusak, karena kesalahan yang dilakukan siswa pada saat praktek. Oleh karena itu perlu dikembangkan media pembelajaran perakitan komputer menggunakan teknologi virtual reality. Penelitian dilaksanakan dengan menggunakan metode penelitian dan pengembangan atau Research and Development (R\&D) model pengembangan four-D (4D). Tahap pengembangan 4D yaitu Define (pendefinisian), Design (perancangan), Develop (pengembangan) dan Disseminate (Pendiseminasian). Model pengembangan multimedia yang digunakan dalam penelitian ini yaitu model pengembangan multimedia versi Luther-Sutopo yang terdiri dari enam tahap yaitu concept, design, material collecting, assembly, testing dan distribution. Pada penelitian ini menggunakan tahapan penelitian yang mengkombinasikan antara 4D dan model pengembangan multimedia versi Luther-Sutopo. Hasil dari penelitian ini adalah media pembelajaran perakitan komputer berbasis virtual reality yang terdiri dari bagian penjelasan komponen hardware dan bagian simulasi perakitan komputer. Media pembelajaran ini dijalankan menggunakan smartphone android, VR-Box serta Controller. Hasil pengujian validitas produk adalah 0,79 dengan kriteria valid. Untuk hasil uji praktikalitas memperoleh nilai 84,11 dengan kriteria sangat praktis. Sedangkan hasil uji efektivitas memperoleh nilai 0,78 dengan kriteria efektivitas tinggi.
\end{abstract}

Katakunci:Perakitan Komputer, Media Pembelajaran, Virtual Reality, 3D

\begin{abstract}
Research is motivated by problems that occur in computer assembly learning. When learning is done is not supported by the number of computer hardware components in accordance with the number of students, so students find it difficult to understand and practice the subject matter. The limited number of components is due to budget constraints for procurement. Many components of visual aids in schools are damaged, due to mistakes made by students during practice. Therefore it is necessary to develop computer assembly learning media using technology of virtual reality. The study was conducted using the research and development method (R\&D) four-D (4D) development model. The 4D development stages are Define, Design, Develop and Disseminate. The multimedia development model used in this research is the Luther-Sutopo version of the multimedia development model which consists of six stages namely concept, design, material collecting, assembly, testing and distribution. In this study using a research phase that combines $4 D$ and Luther-Sutopo version of the multimedia development model. The results of this research are virtual reality based computer assembly learning media consisting of an explanation of the hardware component and a computer assembly simulation section. This learning media is run using an android smartphone, VR-Box and Controller. The results of product validity testing are 0.79 with valid criteria. For the
\end{abstract}


practicality test results obtained a value of 84.11 with very practical criteria. While the effectiveness test results obtained a value of 0.78 with high effectiveness criteria.

Keywords: Computer Assembly, Learning Media, Virtual Reality, 3D

\section{PENDAHULUAN}

Komputer adalah suatu alat elektronik yang dapat memecahkan berbagai masalah dengan memberikan instruksi-instruksi (input digital), lalu diproses untuk memperoleh informasi [1]. Proses yang terjadi di dalam komputer yaitu perhitungan aritmatika dan operasi logika. Komputer terdiri dari berbagai jenis komponen perangkat keras (hardware). Komponen tersebut harus dirakit terlebih dahulu supaya komputer bisa digunakan.

Merakit komputer merupakan teknik menggabungkan komponen-komponen hardware komputer ke dalam casing sampai komputer hidup dan berjalan dengan normal dan siap untuk digunakan [2]. Untuk merakit komputer diperlukan pengetahuan khusus, kesalahan dalam perakitan komputer dapat menyebabkan rusaknya komponen perangkat keras pada komputer tersebut.

Materi mengenai perakitan komputer ini dipelajari oleh siswa pada jurusan Teknik Komputer dan Jaringan (TKJ) di Sekolah Menengah Kejuruan (SMK). Keberhasilan dalam pembelajaran perkaitan komputer salah satunya didukung oleh pemilihan media pembelajaran yang tepat.

Media pembelajaran merupakan alat yang membantu proses belajar mengajar, sehingga pembelajaran menjadi lebih baik [3]. Dalam pembelajaran perakitan komputer media yang dibutuhkan adalah komponen peraga. Komponen peraga tersebut berupa komponen perangkat keras komputer seperti motherboard, prosesor, memori RAM, power supply, DVD room, harddisk, VGA, dan komponen pendukung lainnya.

Studi kasus penelitian ini dilakukan di SMKN 1 Ampek Angkek. Kesimpulan dari penelitian awal yaitu dalam pembelajaran perakitan komputer sekolah masih kekukarangan komponen peraga, sehingga siswa kesulitan dalam memahami dan mempraktekkan materi praktikum. Minimnya jumlah komponen peraga yang dimiliki sekolah disebabkan karena biaya yang cukup mahal untuk membeli komponen tersebut. Komponen peraga juga sudah banyak yang rusak. Rusaknya komponen peraga ini salah satunya disebabkan oleh kesalahan yang dilakukan siswa pada saat pelaksanaan praktikum.

Berdasarkan permasalahan di atas, salah satu solusi yang dapat dilakukan adalah dengan perancangan media pembelajaran yang bisa menggantikan peran dari alat peraga asli. Media pembelajaran tersebut juga harus bisa melakukan proses simulasi dalam perakitan komputer. Sehingga dengan media tersebut kesalahan yang dilakukan oleh siswa pada saat proses perakitan komputer tidak akan berdampak pada rusaknya komponen peraga. Teknologi yang mampu untuk menghasilkan media pembelajaran tersebut adalah virtual reality.

Virtual reality merupakan teknologi yang dapat membuat penggunanya memasuki dunia maya (virtual) dan berinteraksi di dalamnya, karena virtual reality merupakan teknologi berbasis komputer yang mengkombinasikan perangkat khusus input dan output agar pengguna dapat berinteraksi secara mendalam dengan lingkunagan maya seolah-olah berada pada dunia nyata [4]. Media pembelajaran perakitan komputer berbasis virtual reality dapat dimanfaatkan oleh siswa kapanpun dan dimanapun, sehingga siswa dapat belajar tanpa dibatasi ruang dan waktu. Media dipakai secara berulang kali, dan tidak akan merusak objek karena hanya merupakan objek visual.

Penelitian mengenai implementasi teknologi virtual reality sebagai media pembelajaran telah banyak yang melakukannya, diantaranya penelitian yang dilakukan oleh Egi Herlambang, Fakhri Syifaurrahman, dan Moh Ramdani Yusman [5] dalam artikelnya yang berjudul Virtual Reality Sebagai Media Pembelajaran Dalam Perakitan Komputer. Hasil penelitian 
tersebut menyimpulkan bahwa aplikasi virtual reality perancangan komputer mampu dimainkan menggunakan cardboard sehingga dapat berinteraksi dengan lingkungan virtual reality seakan-akan berada di dunia nyata. Aplikasi tersebut memiliki tampilan responsive dan bisa dijalankan di smatrphone bersistem operasi android, dan pengguna harus memakai kacamata Google Cardboard atau VRBox. Penelitian lainnya yaitu penelitian dengan judul Pengembangan Aplikasi Virtual Reality 3D Pengenalan Manusia Purba Bangsa Indonesia Untuk SMA Kelas X (Studi Kasus SMA Negeri 2 Singaraja) [6]. Aplikasi pada penelitian ini memiliki dua mode yaitu mode belajar dan mode bermain, dimana dalam mode belajar pengguna dapat melihat informasi mengenai jenis manusia purba yang ada di Indonesia. Sedangkan dalam mode bermain, pemain dapat memainkan game tentang manusia purba selama 60 detik. Aplikasi ini mendapatkan respon yang positif dari pengguna. Dari hasil perhitungan kepada 20 orang siswa kelas X SMA dengan persentase nilai respon sebesar $82,3 \%$ dengan kriteria "sangat tinggi", sedangkan hasil uji user experience menggunakan UEQ dari 6 komponen penilaian mendapatkan hasil yaitu daya tarik dan stimulasi dengan nilai sangat baik, sedangkan kejelasan, efisiensi, ketepatan dan kebaruan mendapat nilai baik. Selanjutnya penelitian dengan judul Pengembangan Media Pembelajaran Pengenalan Jenis-Jenis Ikan Berbasis Virtual Reality [7]. Pada penelitian ini penulis mengguna beberapa aplikasi yaitu bahasa pemrograman C sharp, Unity untuk pembuatan aplikasi berbasis virtual reality dengan framework GoogleVR SDK for Unity, Blender 3D untuk pembuatan objek 3D ikan dan environment bawah air beserta animasi pergerakan ikan, GIMP untuk membuat tekstur, icon dan gambar latar, dan audacity untuk mengedit suara narasi. Aplikasi ini dapat dipasang pada smartphone android dengan sistem Ice Cream Sandwich ke atas. Penelitian terakhir adalah penilitian yang berjudul Rancangan Game Balinese Fruit Shooter Berbasis Virtual Reality Sebagai Media Pembelajaran
[8]. Pada penelitian ini penulis memperkenalkan buah lokal Bali kepada generasi muda khususnya anak-anak TK melalui game dan membantu proses pembelajaran di TK (Taman Kanak Kanak) dengan sub tema buah-buahan. Hasil akhir dari penelitian ini berupa aplikasi game Balinese Fruit Shooter berbasis virtual reality yang dapat dimainkan melalui komputer dengan alat HTC VIVE. Aplikasi ini memperoleh hasil pengujian kebenaran proses $96 \%$, pengujian kelayakan sebagai game edukasi pengenalan buah lokal Bali dengan hasil $95 \%$, pengujian ahli media mendapatkan hasil $96,5 \%$, dan pengujian ahli isi memperoleh hasil $97,5 \%$.

Berdasarkan paparan dan hasil penelitian sebelumnya, penulis tertarik untuk mengembangkan dan menghasilkan media pembelajaran perakitan komputer dengan teknologi virtual reality. Media tersebut diujicoba di SMKN 1 Ampek Angkek. Pengembangan media ini menggunakan software Blender, dan Unity 3D. Dengan adanya media pembelajaran ini diharapkan dapat membantu siswa untuk memahami materi dan praktek dalam perakitan komputer. Siswa dapat menggunakan media ini kapan saja dan dimana saja, sehingga siswa bisa mengulang-ulang proses simulasi perakitan komputer.

\section{KAJIAN TEORI}

\section{a. Media Pembelajaran [9]}

Menurut terminologinya, kata media berasal dari bahasa latin "medium" yang artinya perantara. Istilah media sama artinya dengan alat peraga, audio visual aids (alat bantu pandang/dengar). Saat ini dikenal dengan instructional media (media pendidikan atau media pembelajaran).

Media pembelajaran adalah suatu alat perantara atau pegantar yang berfungsi untuk menyalurkan pesan atau informasi dari guru kepada siswa agar efektivitas dan efesiensi proses pembelajaran tercapai. Media pembelajaran dapat berbentuk perangkat lunak maupun perangkat keras.

Menurut Nasution [10], manfaat media pembelajaran sebagai alat bantu dalam proses pembelajaran ada empat. Pertama, pengajaran akan lebih menarik perhatian 
siswa sehingga dapat menumbuhkan motivasi belajar. Kedua, bahan pengajaran akan lebih jelas maknanya, sehingga dapat lebih dipahami siswa, serta memungkinkan siswa menguasai tujuan pengajaran dengan baik. Manfaat ketiga yaitu metode pembelajaran akan bervariasi, tidak sematasemata hanya komunikasi verbal melalui penuturan kata-kata lisan pengajar, siswa tidak bosan, dan pengajar tidak kehabisan tenaga. Dan yang keempat siswa lebih banyak melakukan kegiatan belajar, sebab tidak hanya mendengarkan penjelasan dari pengajar saja, tetapi juga aktivitas lain yang dilakukan seperti mengamati, melakukan, mendemonstrasikan dan lain-lainya.

\section{b. Virtual Reality (VR)}

Virtual reality yaitu teknologi yang membuat user dapat berinteraksi dengan lingkungan dunia maya, sehingga user seperti berada di dalam lingkungan tersebut [11]. Kelebihan utama dari virtual reality yaitu pengalaman yang membuat user merasakan sensasi dunia nyata di dalam dunia maya [6]. Dengan virtual reality kita dibawa ke dimensi lain yang penggambaran keadaannya menyerupai bentuk asli dari objek tersebut, padahal kenyataannya kita masih berada di tempat yang sama.

Virtual reality memiliki beberapa elemen kunci [12]. Elemen pertama adalah dunia maya, yang merupakan lingkungan tiga dimensi yang sering direalisasikan melalui media (yaitu rendering, tampilan, dan lain-lain). Elemen kedua yaitu immersion, yaitu persepsi hadir secara fisik di dunia non-fisik, sebuah sensasi yang diciptakan teknologi virtual reality kepada pengguna agar merasakan sebuah lingkungan nyata padahal sebenarnya fiktif. Immersion dibagi dalam tiga jenis, yaitu mental immersion (mental pengguna dibuat merasa seperti berada di dalam lingkungan nyata), physical immersion (membuat fisik penggunanya merasakan suasana di sekitar lingkungan yang diciptakan oleh virtual reality tersebut), dan mentally immersed (sensasi yang dirasakan penggunanya untuk larut dalam lingkungan yang dihasilkan virtual reality). Berikutnya elemen ketiga adalah umpan balik sensory, dimana realitas virtual membutuhkan sebanyak mungkin indera kita untuk disimulasikan. Indra-indra ini termasuk penglihatan (visual), pendengaran (aural), sentuhan (haptic), dan lain sebagainya. Terakhir elemen keempat yaitu interaktivitas, bertugas untuk merespon aksi dari pengguna, sehingga pengguna dapat berinteraksi langsung dalam medan fiktif.

\section{c. Android}

Android adalah sistem operasi berbasis linux yang dimodifikasi untuk perangkat bergerak (mobile device) yang terdiri dari sistem operrasi, middleware, dan aplikasi-aplikasi utama [13]. Android dikembangkan oleh Google, sehingga banyak aplikasi gratis yang ditawarkan di dalamnya. Masyarakat Indonesia sangat familiar dengan smartphone android.

Aplikasi android ditulis dalam bahasa pemrograman Java, yaitu kode Java yang terkompilasi bersama-sama dengan data dan file resources yang dibutuhkan oleh aplikasi yang digabungkan oleh aapt tools menjadi paket android, sebuah file yang ditandai dengan suffix .apk [14]. File ini didistribusikan sebagai aplikasi dan diinstal pada perangkat mobile.

\section{d. Blender [8]}

Blender merupakan perangkat lunak yang bersifat open source digunakan untuk membuat animasi tiga dimensi. Blender dimanfaatkan untuk membuat animasi, efek visual, model cetak 3D, aplikasi 3D interaktif. Blender memiliki beberapa fitur termasuk rigging, animation, simulation, rendering, compositing and motion tracking, even video editing and game creation.

Blender juga sama seperti software 3D pada umumnya seperti 3DS Max, maya dan lightwave, tetapi juga mempunyai perbedaan yang cukup mendasar seperti projek kerja di blender bisa dikerjakan dihampir semua software 3D komersial lainnya. Tampilan blender bisa diatur sesuka hati, mempunyai simulasi physics yang baik dan menggunakan uv yang lebih mudah. Blender juga dapat membuat game karena memilik game engine [15]. 
e. Unity $3 D[7]$

Unity $3 D$ adalah sebuah game engine yang berbasis cross-platform. Unity digunakan untuk membuat aplikasi yang bisa dipakai pada perangkat komputer, ponsel pintar android, iPhone, PS3, dan bahkan $X$-BOX.

Unity sangat mudah digunakan, hanya membuat objek dan diberikan fungsi untuk menjalankan objek tersebut. Dalam setiap objek mempunyai variabel, variabel inilah yang harus dimengerti supaya dapat membuat game yang berkualitas. Berikut ini adalah bagian-bagian dalam Unity, bagian pertama adalah asset, merupakan tempat penyimpanan dalam Unity yang menyimpan suara, gambar, video, dan tekstur. Berikutnya adalah bagian scenes, yaitu area yang berisikan konten-konten dalam game, seperti membuat sebuah level, membuat menu, tampilan tunggu, dan sebagainya. Selanjutnya adalah bagian game objects, yaitu barang yang ada di dalam assets yang dipindah ke dalam scenes, yang dapat digerakkan, diatur ukurannya dan diatur rotasinya. Bagian yang terakhir adalah components, yaitu reaksi baru, bagi objek seperti collision, memunculkan partikel, dan sebagainya. Sedangkan script yang dapat digunakan dalam Unity ada tiga, yaitu Javascript, C\# dan BOO [16].

\section{METODE}

\section{a. Jenis Penelitian}

Penelitian ini merupakan penelitian dan pengembangan. Penelitian dan pengembangan atau research and development (R \& D) merupakan penelitian yang bertujuan untuk menghasilkan produk baru dan menguji keefektifan produk tersebut [17].

\section{b. Langkah Penelitian}

Langkah penelitian yang digunakan adalah model 4D. Model 4D terdiri dari empat tahapan yaitu define, design, develop, dan disseminate [18].

Tahap pertama yaitu tahap pendefinisian (define) yang berisikan langkah-langkah analisis latar belakang dan identifikasi masalah. Tahap kedua adalah tahap perancangan (design) yaitu merancang bentuk awal sketsa media pembelajaran. Tahap ketiga adalah pengembangan (develop), tahap ini merupakan kegiatan untuk membuat media pembelajaran. Dalam pembuatan media pembelajaran penulis menggunakan model pengembangan media Luther-Sutopo. Tahap keempat yaitu tahap penyebaran (disseminate) yang dilakukan untuk mempromosikan produk pengembangan agar bisa diterima pengguna.

\section{c. Model Pengembangan Media}

Model pengembangan media merupakan bentuk pendekatan yang digunakan dalam tahapan mengembangkan suatu media. Pada penelitian ini penulis menggunakan Multimedia Development Life Cycle (MDLC) versi Luther-Sutopo. Pengembangan media Luther-Sutopo terdiri dari enam tahap, yaitu [19] :

1. Concept (konsep), adalah tahap untuk menentukan tujuan dan siapa pengguna program (identifikasi audience). Selain itu menentukan macam aplikasi (presentasi, interaktif, dII) dan tujuan aplikasi (hiburan, pelatihan, pembelajaran, dll).

2. Design (perancangan), adalah tahap membuat spesifikasi mengenai arsitektur program, gaya, tampilan dan kebutuhan material/bahan untuk program.

3. Material Collecting, adalah tahap dimana pengumpulan bahan yang sesuai dengan kebutuhan dilakukan. Tahap ini dapat dikerjakan paralel dengan tahap assembly. Pada beberap kasus, tahap Material Collecting dan tahap Assembly akan dikerjakan secara linear tidak paralel.

4. Assembly (pembuatan), adalah tahap dimana semua objek atau bahan multimedia dibuat. Pembuatan aplikasi didasarkan pada tahap design.

5. Testing, dilakukan setelah selesai tahap pembuatan (assembly) dengan menjalankan aplikasi atau program dan dilihat apakah ada kesalahan atau tidak. Tahap ini disebut juga 
sebagai tahap pengujian alpha (alpha test) dimana pengujian dilakukan oleh pembuat atau lingkungan pembuatnya sendiri.

6. Distribution, tahapan dimana aplikasi disimpan dalam suatu media penyimpanan. Pada tahap ini jika media penyimpanan tidak cukup untuk menampung aplikasinya, maka dilakukan kompresi terhadap aplikasi tersebut.

Produk media pembelajaran perakitan komputer berbasis virtual reality ini akan dilakukan pengujian. Pengujian tersebut adalah uji validitas produk, uji praktikalitas produk, dan uji efektivitas produk. Pengujian dilakukan dengan cara penyebaran angket kepada responden.

\section{HASIL DAN PEMBAHASAN}

\section{A. Hasil Tahap Define}

Pada tahap ini dilakukan kegiatan untuk menemukan potensi dan masalah yang terjadi di lokasi penelitian. Proses yang dilakukan adalah dengan kegiatan observasi dan didukung dengan wawancara terhadap guru dan siswa. Setelah ditemukannya masalah maka dilakukan analisis dan identifikasi untuk menentukan alternatif solusi yang bisa diterapkan.

Hasil yang didapatkan adalah alat peraga berupa komponen perangkat keras untuk praktek perkaitan komputer sangat sedikit, sehingga tida semua siswa bisa melakukan praktek. Alat peraga yang dimiliki sekolah merupakan komponen yang sudah lama, sehingga siswa tidak mengetahui jenis komponen terbaru. Banyaknya alat peraga yang rusak karena kesalahan siswa pada saat pemakaian.

Untuk itu dilakukan perancangan media pembelajaran perakitan komputer dengan teknologi virtual reality. Dengan media tersebut diharapkan dapat mengatasi berbagai masalah yang ditemukan di lokasi penelitian.

\section{B. Hasil Tahap Design}

Pada tahap ini dihasilkan rancangan awal bentuk sketsa media pembelajaran perakitan komputer dengan teknologi virtual reality. Rancangan awal ini memperhatikan hasil diskusi dengan user yang akan menggunakan media ini, yaitu guru dan siswa.

\section{Hasil Tahap Develop}

Tahap develop merupakan langkah pembuatan media pembelajaran. Untuk proses pembuatan media penulis menggunakan model pengembangan media Luther-Sutopo berikut ini.

\section{Hasil Tahap Concept}

Media pembelajaran berbasis virtual reality ini didesain untuk guru komputer supaya dapat digunakan sebagai salah satu media dalam kegiatan belajar mengajar, dan juga dapat digunakan oleh siswa sebagai bahan pembelajaran mandiri. Adapun gagasan dari pembuatan rancangan media pembelajaran berbasis virtual reality ini adalah untuk menarik minat dan perhatian siswa sehingga kegiatan pembelajaran perakitan komputer menjadi lebih mudah dan menyenangkan.

Perancangan media pembelajaran berbasis virtual reality ini hasil akhirnya adalah berupa media pembelajaran interaktif dengan format aplikasi dan VR$B O X$ yang dapat dijalankan pada platform android. Perancangan media pembelajaran berbasis virtual reality ini menggunakan software Blender, dan Unity 3D.

\section{Hasil Tahap Design \\ Pada tahap ini dilakukan} perancangan struktur user interface. Desain interface banyak menggunakan animasi agar siswa tertarik menggunakan aplikasi ini. Unsur tersebut disempurnakan dengan menambahkan sudut pandang 360 derajat. Bentuk desain interface dapat dilihat pada Tabel 1 berikut. 


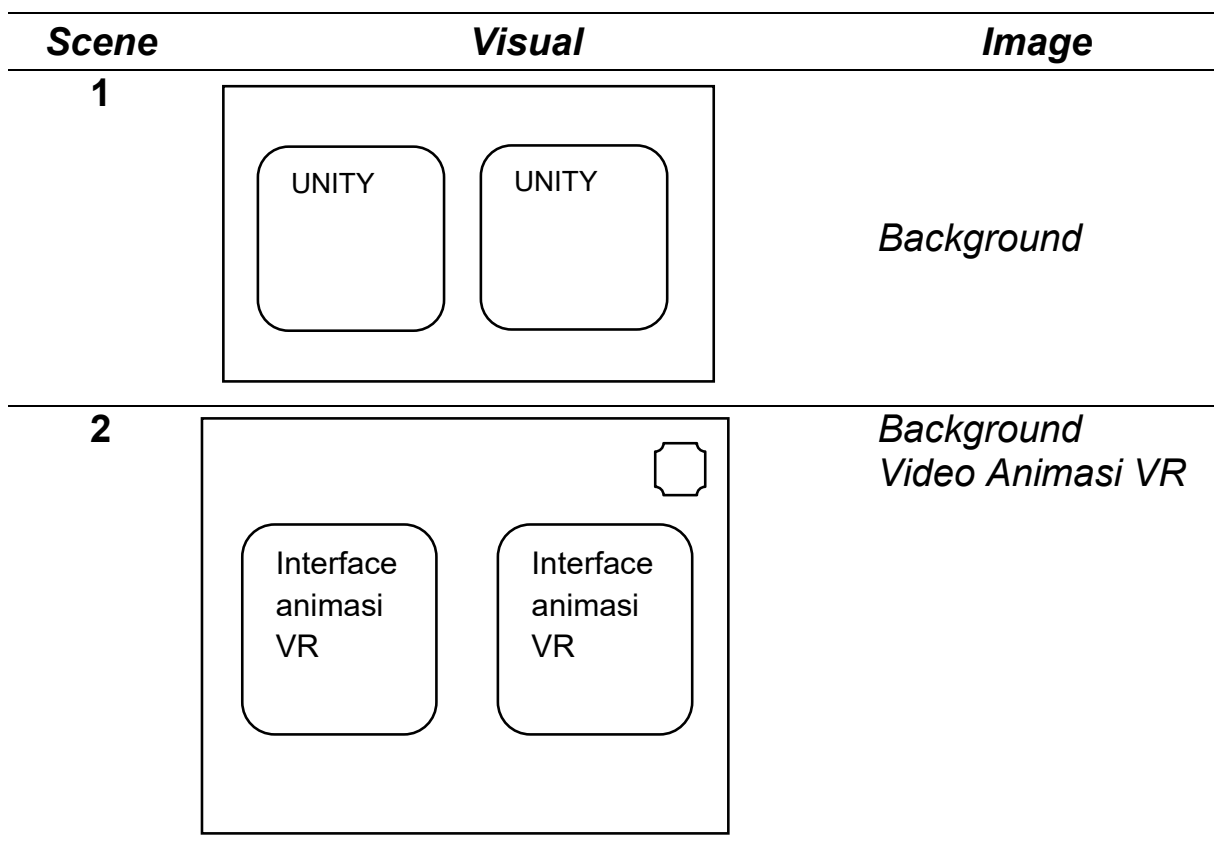

3. Hasil Tahap Material Collecting

Tahapan ini merupakan langkah pengumpulan semua material yang dibutuhkan untuk perancangan media pembelajaran. Material tersebut antara lain adalah konsep dan teori tentang materi perakitan komputer, gambar-gambar yang mendukung teori, dan materi lainnya yang ada kaitannya dengan perakitan komputer. Penyajian materi di dalam media pembelajaran ini mengacu kepada RPP dan silabus yang berlaku di Sekolah.
4. Hasil Tahap Assembly

Tahap ini merupakan langkah untuk pembuatan media pembelajaran. Pada tahap ini dapat diuraikan prosesnya seperti berikut.

a) Pembuatan Objek dan Background

- Modelling

Proses ini adalah pembuatan model objek dalam bentuk 3D di komputer. Gambar 1 dan Gambar 2 berikut ini adalah hasil dari proses modelling

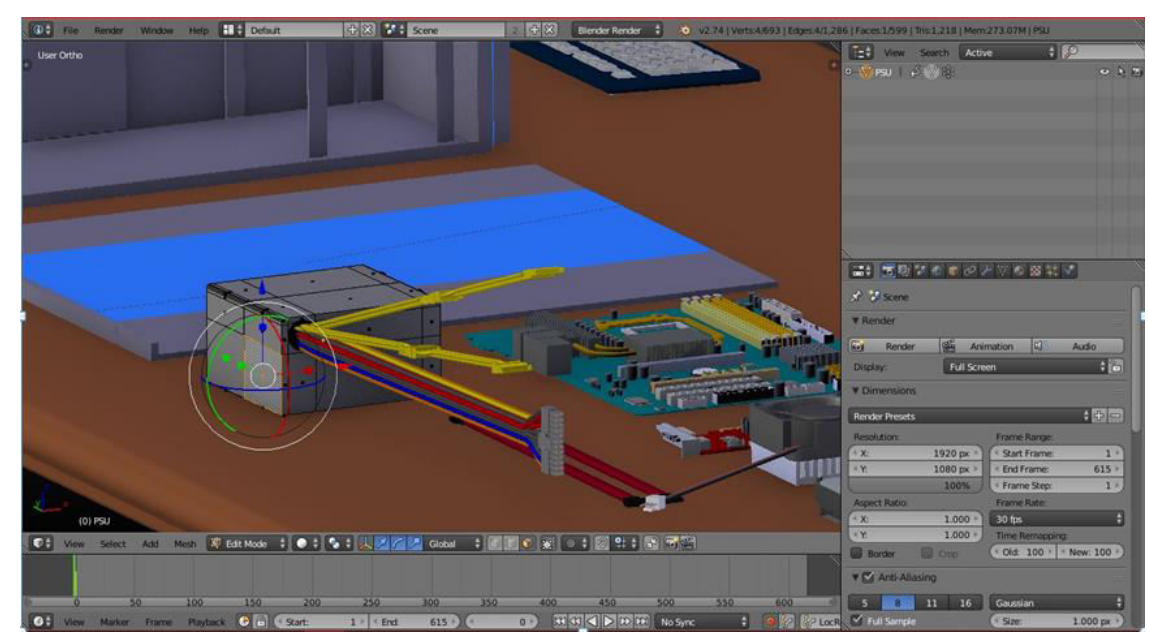

Gambar 1. Pembuatan Model Animasi 3D 


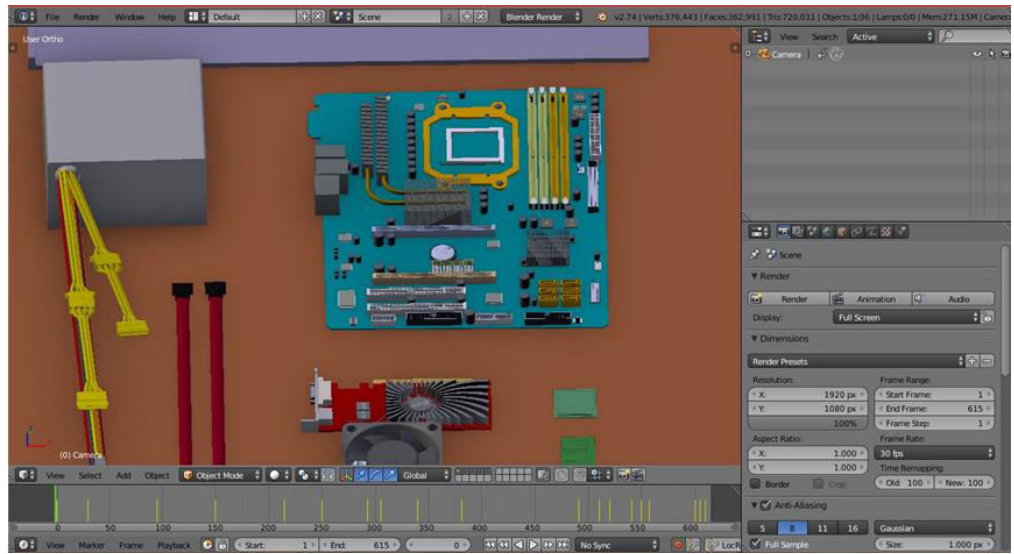

Gambar 2. Hasil Model 3D

- $\quad$ Texturing

Proses ini melakukan pengaturan warna dan material (texture) pada objek.
Gambar 3 berikut ini merupakan hasil proses texturing.

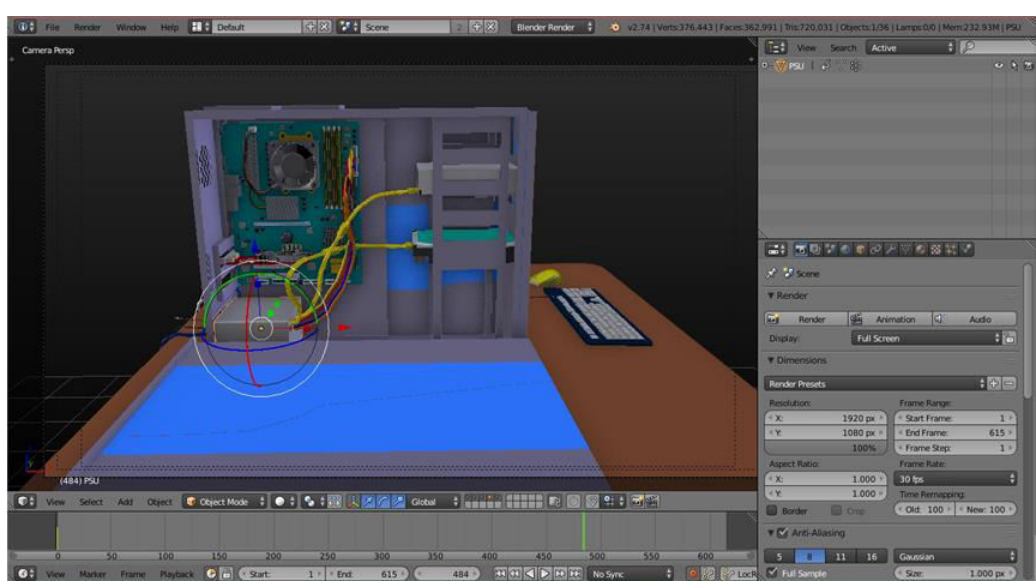

Gambar 3. Texturing Animasi 3D

- $\quad$ Environment Effect

Proses ini membuat efek lingkungan. Gambar 4 merupakan hasil efek lingkungan pada media pembelajaran.

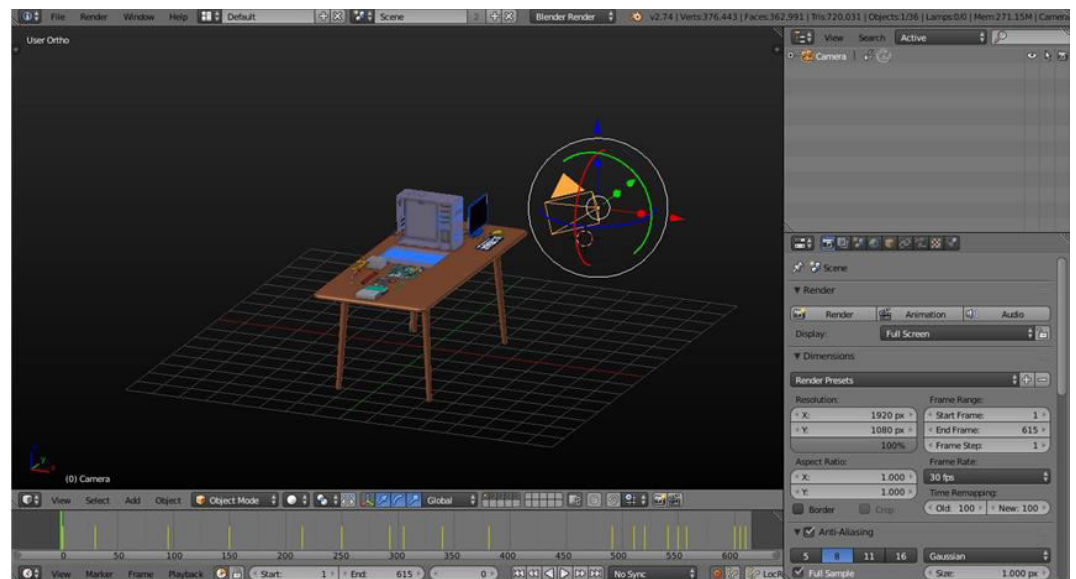

Gambar 4. Environment EffectAnimasi 3D

Jurnal Nasional Pendidikan Teknik Informatika : JANAPATI | 90 
- $\quad$ Visual Effect Virtual Reality

Proses ini merupakan tahapan untuk menghasilkan bentuk tampilan virtual reality. Gambar 5 berikut ini merupakan bentuk tampilan visual dari media pembelajaran yang sudah dirancang.

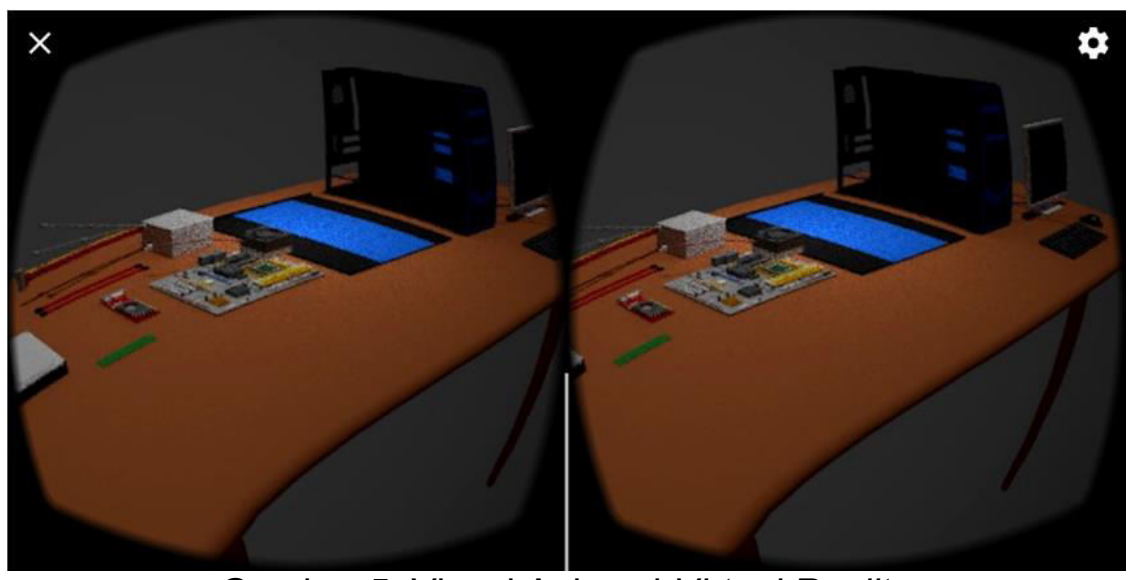

Gambar 5. Visual Animasi Virtual Reality

Alat yang digunakan untuk melihat media pembelajaran berbasis virtual reality adalah VR Box. Gambar 6 berikut ini merupakan alat untuk melihat media pembelajaran berbasis virtual reality.

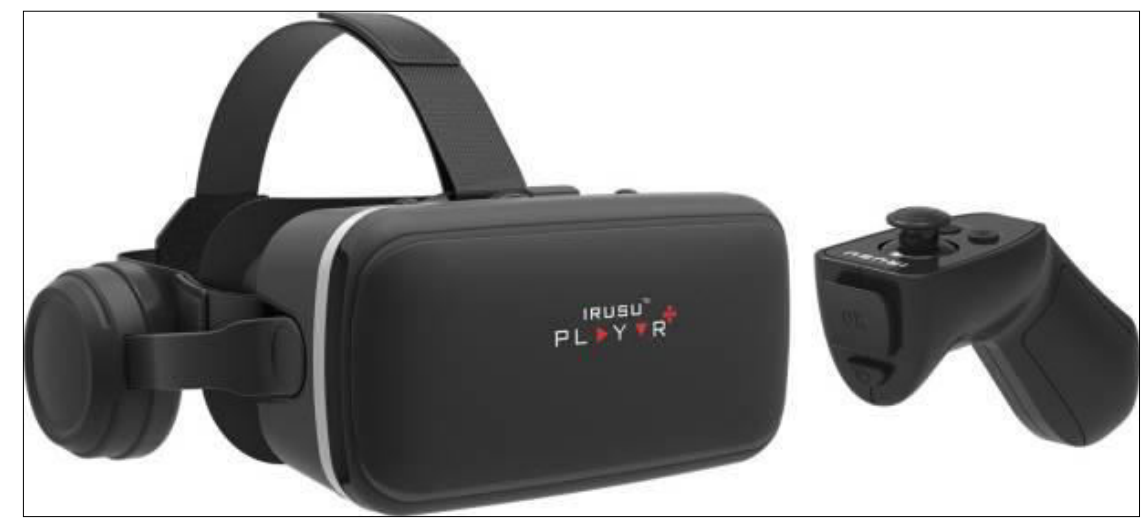

Gambar 6. VR Box

b) Pemograman dengan Actionscript

Actionscript digunakan untuk

menjalankan aksi pada frame maupun pada tombol. Actionscript digunakan utuk untuk menambahkan interaktivitas pada sebuah movie. Actionscript memberikan perintah yang menghasikan suatu aksi atau gerakan pada objek. Perintah actionscript digunakan untuk membuat animasi yang lebih kompleks dan intraktif. Dengan actionsript memungkinkan pembuatan objek yang dapat merespon semua keinginan pengguna [20].
Media pembelajaran yang dirancang pada penelitian ini juga menggunakan actionsript. Actrioncript pada media ini diatur untuk bagian penunjuk objek (mouse), digunakan untuk merespon pada saat menggerakkan objek. Berikut ini actioncsript yang digunakan pada media pembelajaran ini.

using System.Collections;

using System.Collections.Generic;

using UnityEngine;

public class MouseLook : MonoBehaviour \{ 
public enum RotationAxes \{ MouseXAndY $=0$, MouseX = 1, MouseY = 2 \}

public RotationAxes axes =

RotationAxes.MouseXAndY;

public float sensitivity $X=15 \mathrm{~F}$;

public float sensitivity $Y=15 F$;

public float minimumX $=-360 F$;

public float maximum $\mathrm{X}=360 \mathrm{~F}$;

public float minimumY $=-60 \mathrm{~F}$;

public float maximum $\mathrm{Y}=60 \mathrm{~F}$;

float rotation $\mathrm{Y}=\mathrm{OF}$;

void Update()

\{

if (axes == RotationAxes. MouseXAndY)

\{

float rotation $X$ = transform. localEulerAngles.y

+ Input.GetAxis("Mouse X") * sensitivityX;

rotationY += Input.GetAxis("Mouse $Y ")$ * sensitivityY;

rotationY $=$ Mathf.Clamp(rotationY,

minimumY, maximumY);

transform.localEulerAngles = new Vector3(-

rotationY, rotation $\mathrm{X}, 0$ );

\}

else if (axes $==$ RotationAxes. MouseX)

\{

transform.Rotate(0, Input.GetAxis("Mouse

X") * sensitivityX, 0);

\}

else

\{
rotationY += Input.GetAxis("Mouse Y") * sensitivityY;

rotationY $=$ Mathf.Clamp(rotationY, minimumY, maximumY); transform.localEulerAngles $=$ new Vector3(rotationY, transform.localEulerAngles.y, 0);

\}

\}

void Start()

\{

// Make the rigid body not change rotation

if (GetComponent<Rigidbody $>($ ))

GetComponent $<$ Rigidbody $>($ ).freezeRotation = true;

\}

\}

5. Hasil Tahap Testing

Pada tahap ini dilakukan pengujian dengan black box testing. Black box testing merupakan pengujian perangkat lunak dari segi spesifikasi fungsional tanpa menguji desain dan kode program untuk mengetahui apakah fungsi, masukan dan keluaran dari perangkat lunak sesuai dengan spesifikasi yang dibutuhkan [21]. Berikut ini pengujian yang dilakukan pada media pembelajaran.

a) Pengujian 3D Animasi Video

Tabel 2 di bawah ini merupakan hasil pengujian terhadap fungsi 3D animasi video pada media pembelajaran.

Tabel 2. Tabel Pengujian 3D Animasi Video

\begin{tabular}{c|c|c|c}
\hline \multicolumn{4}{c}{ Kasus dan Hasil Uji Coba Media } \\
\hline Data & Yang Diharapkan & Data Normal & Kesimpulan \\
\hline 3D Animasi video & 3D Animasi video & Tampil & Diterima \\
\hline
\end{tabular}

b) Pengujian VR-BOX

Tabel 3 di bawah ini merupakan hasil pengujian terhadap fungsi VR-BOX pada media pembelajaran.

Tabel 3. Tabel Pengujian VR-BOX

\begin{tabular}{c|c|c|c}
\hline \multicolumn{4}{c}{ Kasus dan Hasil Uji Coba Media } \\
\hline Data & Yang Diharapkan & Data Normal & Kesimpulan \\
\hline VR-BOX & $\begin{array}{c}\text { Dapat melihat virtual } \\
\text { reality dengan jelas }\end{array}$ & Berfungsi & Diterima \\
\hline
\end{tabular}


c) Pengujian Joystick

Tabel 4 berikut ini merupakan hasil pengujian terhadap fungsi joystick pada media pembelajaaran.

Tabel 4. Tabel Pengujian Joystick

\begin{tabular}{c|c|c|c}
\hline \multicolumn{4}{c}{ Kasus dan Hasil Uji Coba Media } \\
\hline Data & Yang Diharapkan & Data Normal & Kesimpulan \\
\hline Joystick & $\begin{array}{c}\text { Tombol berfungsi } \\
\text { dengan baik }\end{array}$ & Berfungsi & Diterima \\
\hline
\end{tabular}

6. Hasil Tahap Distribution

Pada tahap ini aplikasi media pembelajaran yang sudah dijadikan file berekstensi .apk disimpan pada media penyimpanan seperti flashdisk, CD, atau DVD. Aplikasi tersebut juga bisa disimpan pada media penyimpanan online. Selanjutnya aplikasi tersebut bisa dipasang pada perangkat android.

\section{Hasil Tahap Disseminate}

Tahap ini merupakan kegiatan untuk penyebaran media pembelajaran perakitan komputer berbasis teknologi virtual reality. Penyebaran dilakukan di lokasi penelitian yaitu SMK N 1 Ampek Angkek. Media pembelajaran disebarkan pada guru dan siswa. Gambar 7 merupakan aktivitas pada saat melakukan penyebaran produk media pembelajaran ke lokasi penelitian.

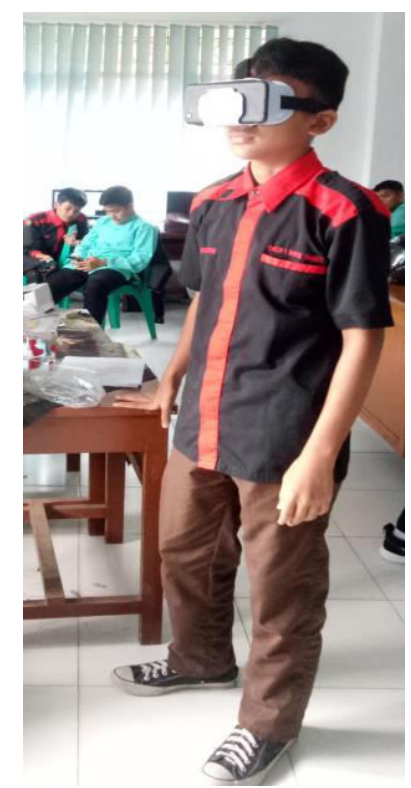

Gambar 7. Kegiatan Siswa Mencoba Media Pembelajaran

Terhadap media pembelajaran perakitan komputer berbasis teknologi virtual reality ini dilakukan pengujian validitas, praktikalitas, dan efektivitas. Uji validitas media pembelajaran dilakukan pada ahli media dan ahli bidang studi. Hasil penilaian uji validitas media pembelajaran ini adalah 0,79. Hasil tersebut menunjukkan media pembelajaran ini valid. Uji praktikalitas dilakukan pada para praktisi. Hasil penilaian uji praktikalitas media pembelajaran ini adalah 84,11. Hasil tersebut menunjukkan media pembelajaran ini sangat praktis. Uji efektivitas dilakukan pada 30 orang siswa kelas X TKJ 1 di SMK N 1 Ampek Angkek. Hasil penilaian uji efektivitas media pembelajaran ini adalah 0,78. Hasil tersebut menunjukkan media pembelajaran ini memiliki efektivitas tinggi. 


\section{SIMPULAN}

Berdasarkan hasil pendefinisian, perancangan, pengembangan dan penyebaran pada penelitian ini dapat disimpulkan bahwa media pembelajaran perakitan komputer berbasis teknologi virtual reality pada kelas $X$ TKJ di SMK N 1 Ampek Angkek membutuhkan perangkat lunak dan perangkat keras. Media pembelajaran ini terdiri dari dua bagian, yaitu bagian penjelasan komponen perangkat keras komputer dan bagian simulasi perakitan perangkat keras komputer. Pada bagian penjelasan komponen perangkat keras komputer mengacu pada materi pembelajaran yang ada di Sekolah. Pada bagian tersebut siswa dikenalkan fungsi, karakteristik dan cara pemasangan komponen. Sedangkan pada bagian simulasi, siswa dapat melakukan simulasi perakitan komponen-komponen komputer. Respon siswa sangat baik, dan siswa sangat antusias menggunakan media pembelajaran ini. Hasil pengujian black box testing menjelaskan bahwa media pembelajaran ini dapat berjalan sesuai dengan tujuan dan harapan.

Berdasarkan hasil penelitian yang telah disampaikan, terdapat beberapa saran bagi peneliti yang akan melakukan penelitian selanjutnya. Pada bagian pengenalan komponen perlu ditambahkan bentuk asli dari komponen tersebut dan penjelasan tentang versi lama dari komponen tersebut. Pengembangan media berikutnya harus mengikuti perkembangan terbaru dari komponen perangkat keras komputer. Untuk pengembagan selanjutnya bisa dibuatkan bagian game perakitan komputer sebagai salah satu bentuk evaluasi pembelajaran.

\section{REFERENSI}

[1] A. Munazilin, Arsitektur Komputer. Yogyakarta: Deepublish, 2017.

[2] Y. Yudhanto, Panduan Pengantar Belajar Hardware dan Software. Solo: Rumah Studio Indonesia, 2018.

[3] C. Kustandi dan B. Sutjipto, Media Pengajaran Manual dan Digital, 1 ed. Bogor: Ghalia Indonesia, 2011.

[4] D. Chandel dan A. Chauhan, "Virtual Reality," Int. J. Sci. Res., vol. 3, no.
10, hal. 1223-1224, 2014.

[5] E. Herlambang, F. Syifaurrahman, dan M. R. Yusman, "Virtual Reality Sebagai Media Pembelajaran Dalam Perakitan Komputer," https://www.academia.edu/39232428 /virtual_reality_sebagai_media_pemb elajaran_dalam_perakitan_komputer, 2019.

[6] N. J. Wardhana, I. K. R. Arthana, dan D. G. H. Divayana, "Pengembangan Aplikasi Virtual Reality 3D Pengenalan Manusia Purba Bangsa Indonesia Untuk SMA Kelas X (Studi Kasus SMA Negeri 2 Singaraja)," J. Nas. Pendidik. Tek. Inform., vol. 8, no. 2, hal. 109-118, 2019.

[7] G. T. A. Kusuma, I. M. A. Wirawan, dan I. K. R. Arthana, "Pengembangan Media Pembelajaran Pengenalan JenisJenis Ikan Berbasis Virtual Reality," J. Nas. Pendidik. Tek. Inform., vol. 6, no. 3, hal. 294-304, 2017.

[8] M. A. Pranata, G. S. Santyadiputra, dan I. G. P. Sindu, "Rancangan Game Balinese Fruit Shooter Berbasis Virtual Reality Sebagai Media Pembelajaran," J. Nas. Pendidik. Tek. Inform., vol. 6, no. 3, hal. 256-270, 2017.

[9] M. R. Sumiharsono dan H. Hasanah, Media Pembelajaran, 2 ed. Jember: Pustaka Abadi, 2018.

[10] T. Nurrita, "Pengembangan Media Pembelajaran Untuk Meningkatkan Hasil Belajar Siswa," Misyakat, vol. 3, no. 1, hal. 171-187, 2018.

[11] K. G. Herlangga, "Virtual Reality dan Perkembangannya," 2016. [Daring]. Tersedia pada: https://www.codepolitan.com/virtualre ality-dan-

\%0D\%0Aperkembangannya.

[12] M. Jamil, "Pemanfaatan Teknologi Virtual Reality (VR) di Perpustakaan," Buletin Perpustakaan Universitas Islam Indonesia, Yogyakarta, hal. 99-113, 2018.

[13] Susanti dan Aifan, "Game Perakitan Komputer Berbasis Mobile Menggunakan Metode Finite State Machines (FSM)," J. Teknol. Dan 
Open Source, vol. 2, no. 1, hal. 2433, 2019.

[14] Mulyadi, Membuat Aplikasi untuk Android. Yogyakarta: Multimedia Center Publishing, 2010.

[15] J. Rori, S. R. Sentinuwo, dan S. Karouw, "Perancangan Aplikasi Panduan Belajar Pengenalan Ortodonsia Menggunakan Animasi 3D," J. Tek. Inform., vol. 8, no. 1, hal. 47-51, 2016.

[16] M. P. Tjahyadi, A. Sinsuw, V. Tulenan, dan S. Sentinuwo, "Prototipe Game Musik Bambu Menggunakan Engine Unity 3D," J. Tek. Inform., vol. 4, no. 2, hal. 1-6, 2014.

[17] E. P. Permana dan D. Nourmavita, "Pengembangan Multimedia Interaktif Pada Mata Pelajaran IPA Materi Mendeskripsikan Daur Hidup Hewan Di Lingkungan Sekitar Siswa Kelas IV Sekolah Dasar," J. IIm. Pendidik. Guru Sekol. Dasar, vol. 10, no. 2, hal. 79-85, 2017.

[18] R. R. Fadila, W. Aprison, dan H. A. Musril, "Perancangan Perizinan Santri Menggunakan Bahasa Pemograman PHP / MySQL Di SMP Nurul Ikhlas," CSRID, vol. 11, no. 2, hal. 84-95, 2019.

[19] H. Sugiarto, "Penerapan Multimedia Development Life Cycle Pada Aplikasi Pengenalan Abjad Dan Angka," Indones. J. Comput. Inf. Technol., vol. 3, no. 1, hal. 26-31, 2018.

[20] L. A. H. Qusyairi, "Pembuatan Media Pembelajaran Fisika Berbasis Macromedia Flash," Islam. J. Keislam. dan IImu Pendidik., vol. 1, no. 1, hal. 97-114, 2019.

[21] W. N. Cholifah, Yulianingsih, dan S. M. Sagita, "Pengujian Black Box Testing Pada Aplikasi Action \& Strategy Berbasis Android Dengan Teknologi Phonegap," J. String, vol. 3, no. 2, hal. 206-210, 2018. 